\title{
SYNTHESIS, CHARACTERIZATION AND MECHANICAL BEHAVIOR OF NICKEL COATED GRAPHITE ON ALUMINUM MATRIX COMPOSITE
}

\author{
Saravana Bhavan $K^{1}$, Suresh $S^{2}$, Vettivel $S^{3}$ \\ ${ }^{1} P G$ student, Department of Mechanical Engineering, University College of Engg, Nagercoil, Anna University Tirunelveli \\ Region, Tamilnadu, India, \\ ${ }^{2}$ Department of Mechanical Engineering, University College of Engg, Nagercoil, Anna University Tirunelveli Region, \\ Nagercoil, Tamilnadu, India \\ ${ }^{3}$ Department of Mechanical Engineering, V V College of Engg., Tisaiyanvilai, Tuticorin, Tamilnadu, India, \\ getksb79@gmail.com,ssuresh2009@gmail.com,vettivel@vvcoe.org
}

\begin{abstract}
In this paper we are going to describe the characterization and mechanical behavior of the Nickel Coated Graphite (NCG) particle reinforced Al6061 metal matrix composite. Many a times, the composites fail to answer the question or fail to serve the purpose for which it is fabricated to. This is due to the less wetting nature between the reinforcement and the matrix and the impossibility of higher percentage of reinforcement addition in to the matrix. However, metal coated reinforcements have been able to overcome these limitations to a very extent. NCG particles reinforced Al6061 matrix with various weight percentages were fabricated by Squeeze casting method. Samples of 0, 5 and 10 wt\% reinforcement addition were synthesized and characterized. Finally some useful conclusions were made.
\end{abstract}

Keywords: Metal Coated Reinforcement; Nickel Coated Graphite; Squeeze Casting; Wetting.

\section{INTRODUCTION}

Development of newer materials with better performance for tribological applications has made researchers to come out with innovative and novel materials to be fabricated from conceptual methods [1]. Recently, Metal Matrix Composites (MMCs) have gone through such a transition [2]. Reinforcing on aluminum alloy is a new dimension of achieving improved mechanical properties while adhering to its natural properties such as good thermal and electrical conductivity and low density. Particularly properties like the thermal conductivity, thermal expansion and stiffness can be specifically regulated within a certain range [3-4].

Many reinforcements proved to yield same results on aluminum alloy [5]. The usual reinforcements inside aluminum matrix would be ceramics like $\mathrm{SiC}, \mathrm{Al}_{2} \mathrm{O}_{3}, \mathrm{AlN}$, $\mathrm{B}_{4} \mathrm{C}, \mathrm{TiC}$ and $\mathrm{TiB}_{2}$ [6]. These reinforcements are either purchased or being processed using several techniques to fabricate out of. This makes the cost of reinforcement costlier [5]. Also such fabricated composites have proved to have low ductility than conventional alloys [6-7].

A promising, effective, economic and a good substitutional reinforcement with a self lubricating property could be graphite [8]. From older times, graphite has been recognized as a material having high strength to mass ratio, low density and a best solid lubricant [9]. Graphite fibre reinforcement has found wide application in polymer and epoxy based composites [10]. As well, graphite particle reinforcement has also found wide application in wear prone areas and in places where external lubrication is difficult or not possible [11]. Rohatgi et al. [12] also concludes that the rate of wear resistance is improved by mixing graphite particles into the alloy.

In electronic industries, high temperatures and temperature cycles have a strong impact on the reliability of the assembly [13]. An improvement of durability of the electronic system can be achieved by using parts made out of Aluminum Graphite (Al-Gr), because the Al-Gr's coefficient of thermal expansion (CTE) is very similar to the CTE of several ceramics and semiconductors [14]. Furthermore, Al-Gr has a lower density, in comparison to conventional materials as copper, which leads to a vital weight reduction [15]. Possible applications of parts made of Al-Gr are Base plates or coolers for power semiconductor devices, heat sinks and heat spreaders, Lids, substrates, interposer, USB flash drives, housings and similar complex structures, which are used in power electronics, microelectronics and optoelectronics [16]. 
Though these benefits and applications overweighs it's as cast alloy and ceramic reinforced one, the mode of manufacture, the difficulties entitled have confined the use of such good property metals to be applied in various engineering applications. The main problem faced with not only such composites but with almost all types and category of composite is being the property of wetting that must be exhibited between the matrix and the reinforcement [17]. If this phenomenon is better, good is the result of the bonding in fabricated composite and if poor then it results in inadequate bonding between the matrix and the reinforcement [18].

Landry et al [19] tried methods of improving wettability of reinforcement with matrix by casting under $700-800^{\circ} \mathrm{C}$ temperature keeping under long time exposure in the melt but on solidification the segregation of reinforcement was unavoidable and became a heterogeneous composite. Steffens et al [20] tried to increase the wettability by fabricating with temperature above $900^{\circ} \mathrm{C}$ up to $1000^{\circ} \mathrm{C}$ where an interfacial reaction occurred between aluminum and the reinforcement which yielded brittle aluminum carbide that broke the composite due to expansion in humid environment. Stephenson et al [21] reported that coating of nickel on reinforcement and introducing inside the matrix produced a good wettable composite. This wettable wear resistance aluminum metal matrix composite is commercially used in automobile engine cylinder liner and brake rotor [22]. Ip et al [23], experiments the behavior of aluminum droplet on various substrates and uses sessile drop method to confine the contact angle to a minimum for coated reinforcement with aluminum matrix. He proves that the angle is very low to $4^{\circ}$ on nickel coated graphite substrate.

In this article, firstly we fabricate Aluminum Matrix Composite (AMC) reinforced with Nickel Coated Graphite (NCG) and AMC with separate dispersion of Nickel (Ni) powder and Graphite (Gr) powder as reinforcement using Squeeze casting method. Secondly, both types of composites were characterized for tensile, acoustic and hardness tests and the results were compared and tabulated. Thirdly, the microscopic examination of the tested samples was done to depict the nature of bonding and force between the matrix and the reinforcement.

\section{EXPERIMENTAL DETAILS}

\subsection{Materials}

The aluminum (AA6061 T6) grade was used as the matrix material. It was purchased from PMC Corporation, as blanks and was used for casting. It has very good corrosion resistance and very good weldability.

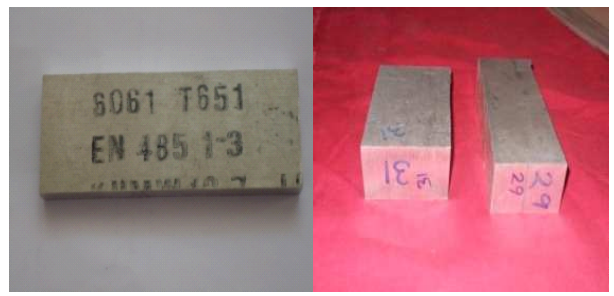

Fig - 1: Raw Material - AA 6061 T6

This alloy also offers good finishing characteristics and responds well to anodizing. The composition of AA 6061 is given in table 1.

Table - 1: Chemical composition of Al 6061

\begin{tabular}{|c|c|c|c|c|c|c|c|c|}
\hline $\begin{array}{c}\text { Elemen } \\
\mathrm{t}\end{array}$ & $\mathrm{Mg}$ & $\mathrm{Fe}$ & $\mathrm{Si}$ & $\mathrm{Cu}$ & $\mathrm{Mn}$ & $\mathrm{V}$ & $\mathrm{Ti}$ & $\mathrm{Al}$ \\
\hline $\begin{array}{c}\text { Weight } \\
\%\end{array}$ & $\begin{array}{c}1.0 \\
8\end{array}$ & $\begin{array}{c}0.1 \\
7\end{array}$ & $\begin{array}{c}0.6 \\
3\end{array}$ & $\begin{array}{c}0.3 \\
2\end{array}$ & $\begin{array}{c}0.5 \\
2\end{array}$ & $\begin{array}{c}0.0 \\
1\end{array}$ & $\begin{array}{c}0.0 \\
2\end{array}$ & $\begin{array}{c}\text { Res } \\
\mathrm{t}\end{array}$ \\
\hline
\end{tabular}

The reinforcement powder is Nickel coated Graphite from Chengdu Nuclear 857 Co., The particle size is -300 mesh. The particles were added as reinforcement with weight $\%$ of 0,5 and 10 within AA matrix.

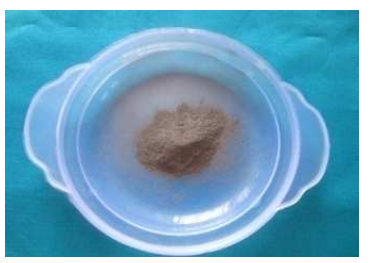

Fig - 2: Nickel Coated Graphite Powder

The SEM image of NCG Powder sample is shown in Fig.3. The images clearly show uniform coating of nickel powders on each particulate of graphite.

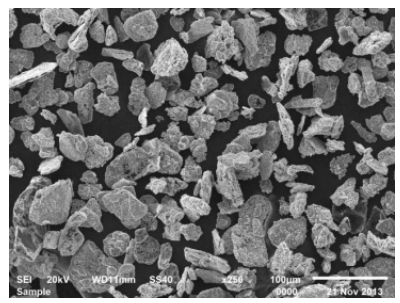

Fig - 3: SEM Image of Nickel Coated Graphite Powder

Graphite powder used in this work is of 400 mesh size. It is added separately in to the matrix melt after preheating. The SEM images of the Graphite powder is shown in Fig.4. 


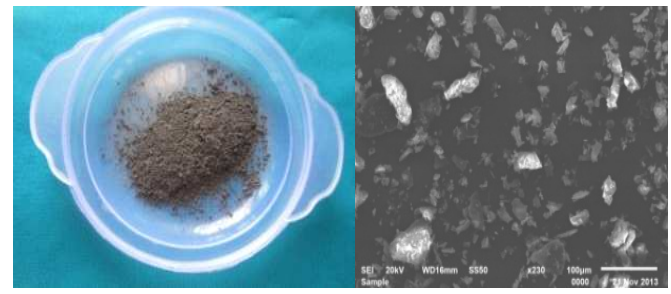

Fig - 4: Images of Graphite Powder sample

Nickel powder of 1 micron size, $99.9 \%$ purity purchased from J \& J Groups was used. The images of the sample are shown in Fig.5.

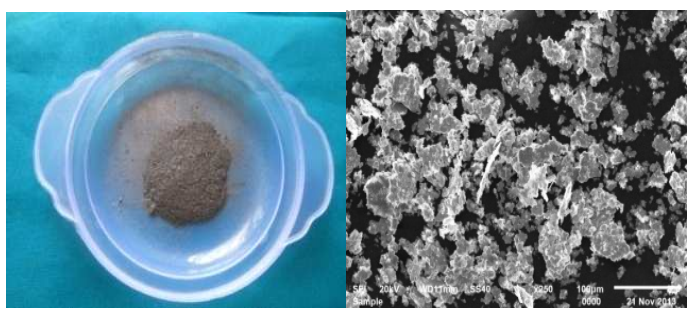

Fig - 5: Images of Nickel Powder sample

\subsection{Squeeze Casting Unit}

The composites are fabricated with a squeeze caster machine. The melt is discharged out of the furnace by bottom pour path setup. The gravity poured sample is now squeezed through a squeezer ram with a pressure of 50T and a setting time of 10secs. The experimental setup of this facility is shown in Fig.6.

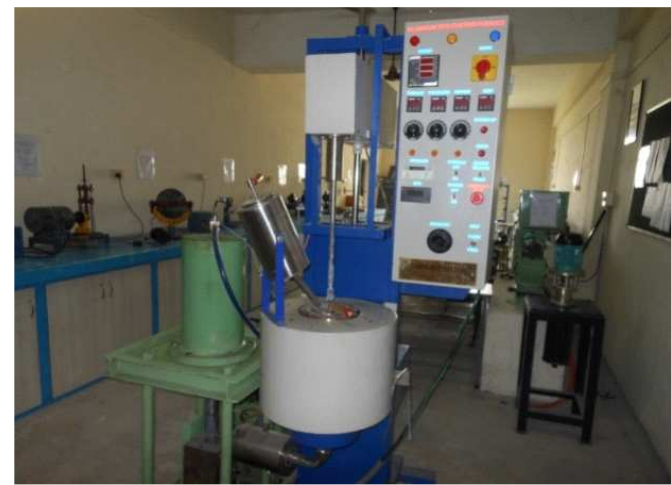

Fig - 6: Squeeze Casting Machine Setup

\subsection{Fabrication}

Initially, the furnace was turned on to heat to a temperature above $850^{\circ} \mathrm{C}$ and a holding time up to $1 \mathrm{hr}$. Aluminum alloy blocks were dropped in to the furnace allowing it to melt in the furnace. Meanwhile the powders which are to be added as reinforcement were preheated at $600-800^{\circ} \mathrm{C}$. The reinforcement is slowly added in to the aluminum matrix melt through a dispenser while maintaining a constant stirring of $400 \mathrm{rpm}$ for 6-7secs with a motorized stirrer. After ensuring the proper distribution of the reinforcement in to the matrix the drain plug is opened so that the melt flows through the pathway which is preheated to a temp of $650^{\circ} \mathrm{C}$. The ram of the squeezer is now pushed forward so that the entire melt is subjected to a pressure of 50 tones with a setting time of 810secs. This squeezing enhances the distribution of reinforcement uniformly in to the matrix there by minimizing the formation of pores in the cast samples.

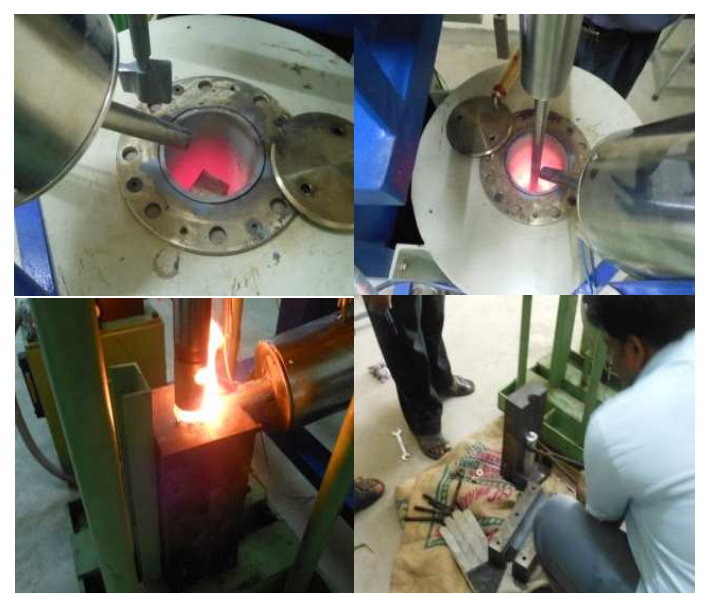

Fig - 7: Images of Composite Fabrication

The samples were fabricated as two sets: the first being the samples under reinforcement of NCG with 0, 5 and $10 \mathrm{wt} \%$ addition into the matrix melt and the second being the mixture addition of Ni powder and Graphite powder in the proportion of 0,5 and $10 \mathrm{wt} \%$ in to the melt matrix. The cast samples were indexed so as to identify it for varying proportion of reinforcement mixture.

\subsection{Composite Material Testing}

The prepared samples were carefully machined to suit to the best standards for each testing. Here ASTM standard is followed for testing. Tensile samples were prepared with a diameter of $16 \mathrm{~mm}$ and length of $140 \mathrm{~mm}$. The length of the reduced section is $80 \mathrm{~mm}$ and the diameter at the gauge section is $12 \mathrm{~mm}$.

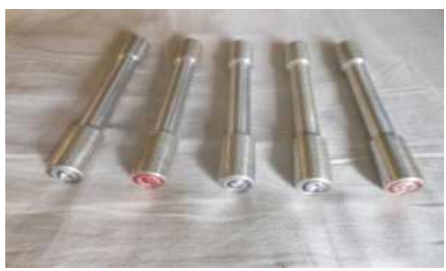

Fig - 8: Samples for Tensile Test 
The composites were tested for hardness in a microhardness testing machine. The samples were machined to the standard for hardness testing. After machining the samples were polished in papers of varying grit size. The polished samples were now placed on the tester for hardness testing.

Structural examination of the so prepared composite and the tested sample were done with a Scanning Electron Microscope (SEM) under varying magnification and power.

\section{RESULTS AND DISCUSSION}

\subsection{Tensile Testing}

The samples were tested under standard testing condition. The specimen after testing is shown in Fig.9.

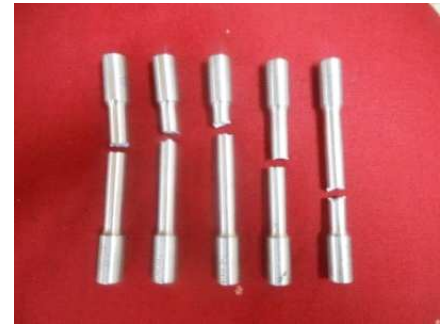

Fig - 9: Samples after Tensile Test

The test values are tabulated in Table. 2 and the corresponding output graph of as-cast aluminum, aluminum with separate dispersion of nickel - graphite powders and aluminum with nickel coated graphite powders are shown in Fig-10, 11 and 12.

Table - 2: Tensile Test Results

\begin{tabular}{|c|c|c|c|}
\hline Sample & $\begin{array}{c}\text { Peak Load } \\
(\mathrm{kN})\end{array}$ & $\begin{array}{c}\text { UTS } \\
(\mathrm{MPa})\end{array}$ & $\begin{array}{c}\% \\
\text { Elongation }\end{array}$ \\
\hline $\mathrm{Al} 6061$ as-cast & 10.245 & 91 & 16.257 \\
\hline $\mathrm{Al} / \mathrm{Ni}-\mathrm{Gr}(5 \%)$ & 10.01 & 88 & 7.857 \\
\hline $\mathrm{Al} / \mathrm{Ni}-\mathrm{Gr}(10 \%)$ & 9.55 & 84 & 7.443 \\
\hline $\mathrm{Al} / \mathrm{NCG}(5 \%)$ & 20.095 & 178 & 12.6 \\
\hline $\mathrm{Al} / \mathrm{NCG}(10 \%)$ & 21.23 & 183 & 11.4 \\
\hline
\end{tabular}

From the table it is evident that the percentage addition of NCG reinforcement has a positive effect on the tensile strength (UTS) when compared with the base alloy and with a reduction in \% of Elongation. But a controversial effect is observed on reinforcing nickel and graphite powders separately.

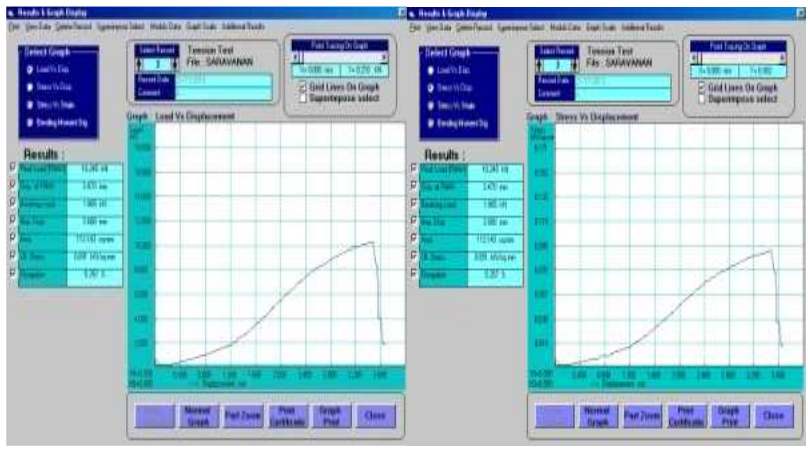

Fig - 10: Tensile Graph of As-cast Aluminum Sample

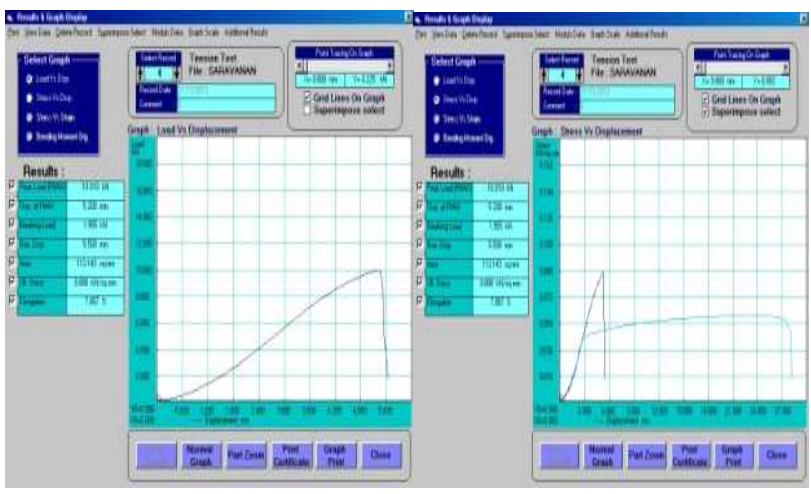

Fig - 11: Tensile Graph of Al-Ni-Gr (5 wt\%) Composite

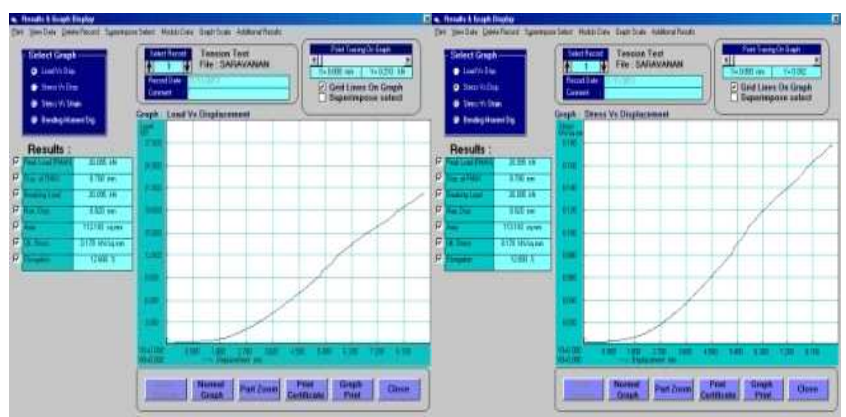

Fig-12: Tensile Graph of Al-NCG (5 wt\%) Composite

Devinder Yadav [24] reported that for $7 \% \mathrm{Ni}$ addition in to matrix Al 1050 yielded an UTS increase of $60 \%$ comparing the base Al 1050 whereas here the result shows a $10 \%$ reduction in UTS for $5 \%$ of $\mathrm{Ni}$ addition in to the aluminum matrix. This reduction in UTS may be due to the formation of brittle $\mathrm{Al}_{3} \mathrm{Ni}$ phases at the region of interface [25]. It can also be found that the statement proposed by, Devinder Yadav [24] regarding the \% of Elongation is true for our samples. It is noticeable that this reduction in \% Elongation value is very drastic for separately dispersed composite when compared with coated reinforced composite. 
Rams et al [25], proved that the wettability of carbon fibre reinforcement having coated with nickel gave better images to show that the matrix is mostly homogeneous which may yield better mechanical properties than uncoated reinforcement. With this proceeding we too have better results for strength (UTS) value of coated reinforcement compared with uncoated one.

\subsection{Microhardness Test}

Microhardness test for the prepared samples is conducted as per the test specification and conditions on a Vickers Hardness tester. The applied load for indentation on a diamond indenter is $0.3 \mathrm{~kg}$ and the time of indentation is 10 secs for all samples. The results of the readings observed are tabulated in Table.3. It is evident from the table values that the impact of NCG reinforcement is better than $\mathrm{Ni}-\mathrm{Gr}$ reinforcement as expected. The values of the Ni-Gr for both wt\% additions happen to be greater than the as-cast sample but it could have been even better if the formation of intermetallic could have been avoided. Devinder Yadav [3] has reduced the formation of intermetallic by the process of fabricating the samples through friction stir processing (FSP). However, the greater values of composites than its alloy have given satisfactory results.

Table - 3: Hardness Test Result

\begin{tabular}{|c|c|c|c|c|}
\hline \multirow{2}{*}{ Sample } & \multicolumn{3}{|c|}{ Vickers Hardness Number } & \multirow{2}{*}{$\begin{array}{l}\text { Average } \\
\text { Hardness }\end{array}$} \\
\hline & Trial 1 & Trial 2 & Trial 3 & \\
\hline $\begin{array}{c}\text { Al } 6061 \\
\text { as-cast }\end{array}$ & 65.7 & 67.2 & 65.7 & 66.2 \\
\hline $\begin{array}{c}\mathrm{Al} / \mathrm{Ni}-\mathrm{Gr} \\
(5 \%)\end{array}$ & 68.7 & 70.2 & 71.8 & 70.2 \\
\hline $\begin{array}{c}\mathrm{Al} / \mathrm{Ni}-\mathrm{Gr} \\
(10 \%)\end{array}$ & 77 & 75.2 & 78.8 & 77 \\
\hline $\begin{array}{c}\mathrm{Al} / \mathrm{NCG} \\
(5 \%)\end{array}$ & 75.2 & 75.2 & 77 & 75.8 \\
\hline $\begin{array}{c}\mathrm{Al} / \mathrm{NCG} \\
(10 \%)\end{array}$ & 91.4 & 84.8 & 89.1 & 88.4 \\
\hline
\end{tabular}

\subsection{SEM Examination of Tensile Tested Samples}

The fracture area examination under Scanning Electron Microscope (SEM) reveals several facts that have made the composites to exhibit such mechanical property enhancement. In Fig.13 (a \& b) shows the micrographs on Ni-Gr reinforcement taken with lower magnification. This image confirms the existence of medium and higher size of voids that affect the mechanical properties. Whereas, the micrographs of the sample with NCG coating shown in Fig.13(c \& d), clearly conveys less formation of voids on the fractured surface of the samples. This gives the sample in Fig. $\mathrm{c}$ and $\mathrm{d}$ to be more ductile in nature than the samples in Fig. $a$ and $b$.

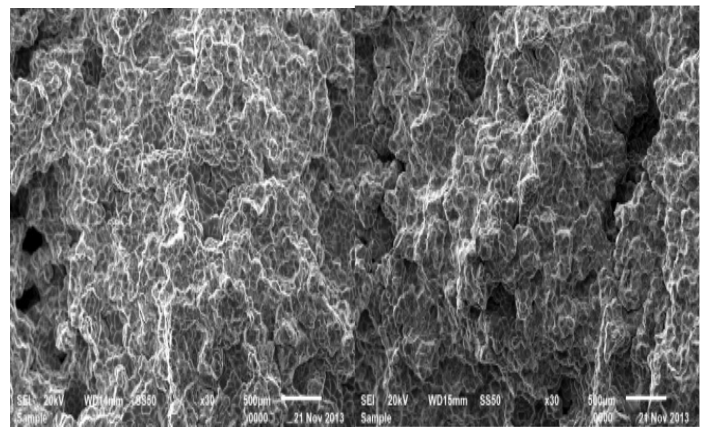

(a)

(b)

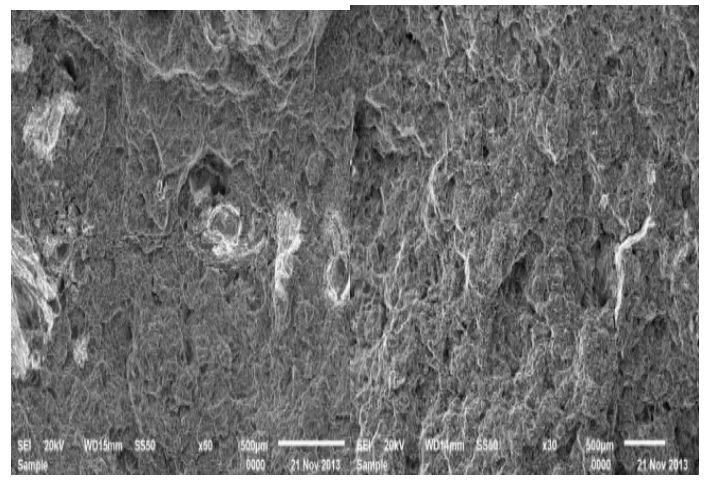

(c)

(d)

A closer examination of the casted composite samples shows that in Fig. e and $f$ the grain boundaries are very distinct also the nickel is found to be distributed in aluminum matrix. Here the graphite particles are found only as traces on the fracture surface. This distribution is the reason for having low value of hardness compared with NCG composites.

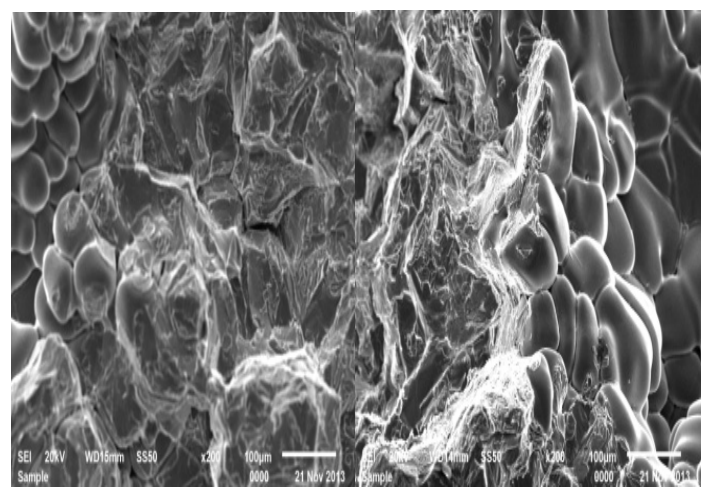

(e)

(f) 


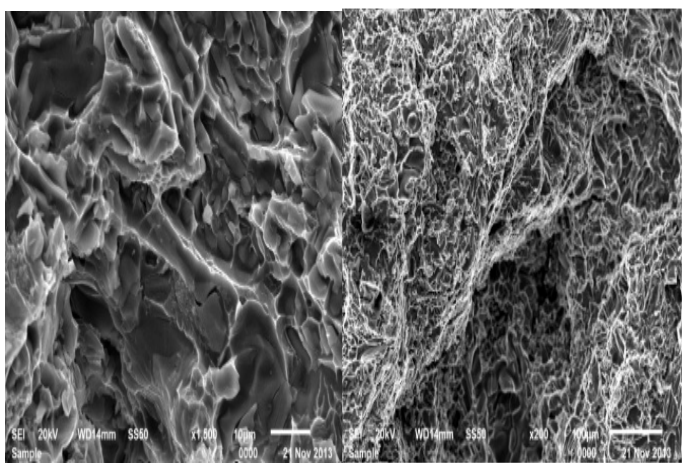

(g)

(h)

Fig-13: Fracture morphology of AA6061 composites containing Ni-Gr and NCG reinforcements: Under low magnification (a) $5 \mathrm{wt} \% \mathrm{Ni-Gr}$, (b) $10 \mathrm{wt} \%$ of Ni-Gr, (c) 5 wt.\% NCG, (d) 10 wt.\% NCG, Under high magnification (e) $5 \mathrm{wt} \% \mathrm{Ni}-\mathrm{Gr}$, (f) $10 \mathrm{wt} . \%$ of Ni-Gr, (g) 5 wt.\% NCG, (h) 10 wt.\% NCG

The Fig. $g$ and $h$ shows the wetted graphite inside the aluminum matrix. This is because of the NCG reinforcement added which gave better UTS and hardness values. Also we can signify the macroscopic brittle fracture and microscopic ductile fracture from the images. In Fig. g Graphite particles remain intact in several places which provide evidence to the existence of good bonding between the aluminum matrix and reinforcement particles.

\section{CONCLUSIONS}

1. The tensile test values predicted good results for NCG reinforced composite than for ordinary reinforced ones.

2. The NCG reinforced composites were able to achieve better hardness values than that of the as-cast samples and separately dispersed reinforcements.

3. The SEM micrograph very clearly shows less formation of voids in NCG reinforced composites. This reduces the brittleness and retains the ductility to some extent and then allows for fracture.

4. Graphite being less dense was thought to float or get skimmed away by the melt when more percentage needs to be added. But with nickel coating on graphite we were able to achieve graphite particles a little denser than graphite. It is also due to this reason we are able to go in for higher percentage of graphite addition.

5. The intact bonding between the reinforcement and the matrix plays a vital role in deciding the behavior of composite. We have achieved this intact layer by reducing the layer of segregation and improving performance.

\section{REFERENCES}

[1]. T.W.CLYNE and P.J.WITHERS. "An introduction to metal matrix composites", 1st ed., Cambridge University Press, Cambridge, 1993, p 1-10

[2]. K.K.CHAWLA. "Composite Materials", 2nd ed., Springer, New York, 1998, p 3-5.

[3]. L. KENPFER. Mech. Eng. 8 (1990) 19-22.

[4]. M. HUNT. Mech Eng. 7 (1989) 43-46.

[5]. I.A. IBRAHIM, "Particulate Reinforced Metal Matrix Composites - A Review”, J. Mater. Sci., 1991, 26(5), p. 1137-1156

[6]. Y.B. TANG, Y.Q. LIU, C.H. SUN, AND H.T. CONG. "AlN nanowires for Al-based composites with high strength and low thermal expansion", J. Mater. Res., Vol. 22, No. 10, Oct 2007, p 2711.

[7]. S. RAY, "Review Synthesis of Cast Metal Matrix Particulate Composites",J. Mater. Sci., 1993, 28(20), p 5397-5413

[8]. SHUKOR, M. S, AND SAIFUDIN, H. Y. "Properties determination of self-lubricating al-graphite composites", Journal of Advanced Manufacturing and Technology, Vol. 4 No. 1 Jan-June 2010

[9]. S.BISWAS and P.K.ROHATGI. "Tribological properties of cast graphitic aluminum composites", Tribol, Int., 1983, 16(2), p 89-102.

[10]. Y.LIU, P.K.ROHATGI, S.RAY. Metall. Trans. A 24A (1992) 151-159.

[11]. M.L.TED GUO, CHI. - Y.A. TSAO. "Tribological behavior of aluminum/sic/nickel-coated graphite hybrid composites", Material Science and Engineering A333 (2002) 134-145.

[12]. P.K.ROHATGI, B.C.PAI. "Effect of microstructure and mechanical properties on the seizure resistance of cast aluminum alloys", Wear 28 (1974) 353-367.

[13]. M K SURAPPA. "Aluminium matrix composites: challenges and opportunities", Sadhana, vol.28, Parts 1 \& 2, 2003, p $319-334$.

[14]. VARUZAN KEVORKIJAN. "Development of $A l$ MMC composites for automotive industry", Yugoslav Association of Metallurgical Engineers.

[15]. J ELIASSION and R SANDSTROM. "Application of aluminium matrix composites", Key Engineering Materials Vols. 104 - 107 (1995) p 3 - 36.

[16]. F.AKHLAGHI and S.A.PELASEYYED. "Characterization of aluminium/graphite particulate composites synthesized using novel method termed - in situ powder metallurgy", Mater. Sci. Eng. A, 2004, 385, p 258-266.

[17]. N.EUSTATHOPOULOS, J.C.JOUD, P.DESRE and J.M.HIETER. "The wetting of carbon by aluminium and aluminium alloys", J. Mater. Sci., 1974, 9(8), p 1233-1242.

[18]. A.SATO and R.MEHRABIAN. "Aluminium matrix composited: fabrication and properties", Metall. Mater. Trans. B, 1976, 7(3), p 443-451. 
[19]. LANDRY K, KALOGEROPOULOU S, EUSTATHOPOULOS E. "Wettability of carbon by aluminum and aluminum alloys", Mat Sci Eng A 1998; 254 (1-2):99-111.

[20]. STEFFENS HD, REZNIK B, KRUZHANOV V, DUDZINSKI W. "Carbide formation in aluminumcarbon fibre-reinforced composites", J Mater Sci 1997; 32(20):5413-7.

[21]. T.F.STEPHENSON, A.M.E.WARNER, S.WILSON, A.T.ALPAS, P.K.ROHATGI. Proc. Mater. Week 1996, TMS/ASM, 1996.

[22]. J.A.E.BELL, A.M.E.WARNER, T.F.STEPHENSON, E.SIEGRIST, Proc. Mater. Week 1996, TMS/ASM, 1996.

[23]. S.W.IP, R.SRIDHAR, J.M.TOGURI, T.F.STEPHENSON, A.M.E.WARNER. "Wettability of nickel coated graphite by aluminum". Mat. Sci Eng. A244 (1998) 31-38.

[24]. DEVINDER YADAV, RANJIT BAURI. "Nickel particle embedded aluminium matrix composite with high ductility", Materials Letters 64 (2010) 664-667.

[25]. J.RAMS, A.URENA, M.D.ESCALERA, M.SANCHEZ. "Electroless nickel coated short carbon fibres in aluminium matrix composites". Composites: Part A 38 (2007) 566-575. 